\title{
Soluble A $\beta$ Seeds Are Potent Inducers of Cerebral $\beta$-Amyloid Deposition
}

\author{
Franziska Langer, ${ }^{1,2,3}$ Yvonne S. Eisele, ${ }^{1,2}$ Sarah K. Fritschi, ${ }^{1,2,3}$ Matthias Staufenbiel, ${ }^{4}$ Lary C. Walker, ${ }^{5}$ \\ and Mathias Jucker ${ }^{1,2}$ \\ ${ }^{1}$ Department of Cellular Neurology, Hertie Institute for Clinical Brain Research, University of Tübingen, D-72076 Tübingen, Germany, ${ }^{2}$ DZNE, German \\ Center for Neurodegenerative Diseases, D-72076 Tübingen, Germany, ${ }^{3}$ Graduate School of Cellular and Molecular Neuroscience, University of Tübingen, \\ D-72074 Tübingen, Germany, ${ }^{4}$ Novartis Institutes for Biomedical Research, Neuroscience Discovery, CH-4002 Basel, Switzerland, and ${ }^{5}$ Yerkes National \\ Primate Research Center and Department of Neurology, Emory University, Atlanta, Georgia 30329
}

Cerebral $\beta$-amyloidosis and associated pathologies can be exogenously induced by the intracerebral injection of small amounts of pathogenic $\mathrm{A} \beta$-containing brain extract into young $\beta$-amyloid precursor protein (APP) transgenic mice. The probable $\beta$-amyloidinducing factor in the brain extract has been identified as a species of aggregated $\mathrm{A} \beta$ that is generated in its most effective conformation or composition in vivo. Here we report that $\mathrm{A} \beta$ in the brain extract is more proteinase $\mathrm{K}(\mathrm{PK})$ resistant than is synthetic fibrillar $\mathrm{A} \beta$, and that this PK-resistant fraction of the brain extract retains the capacity to induce $\beta$-amyloid deposition upon intracerebral injection in young, pre-depositing APP23 transgenic mice. After ultracentrifugation of the brain extract, $<0.05 \%$ of the A $\beta$ remained in the supernatant fraction, and these soluble $\mathrm{A} \beta$ species were largely $\mathrm{PK}$ sensitive. However, upon intracerebral injection, this soluble fraction accounted for up to $30 \%$ of the $\beta$-amyloid induction observed with the unfractionated extract. Fragmentation of the $\mathrm{A} \beta$ seeds by extended sonication increased the seeding capacity of the brain extract. In summary, these results suggest that multiple $A \beta$ assemblies, with various $\mathrm{PK}$ sensitivities, are capable of inducing $\beta$-amyloid aggregation in vivo. The finding that small and soluble $\mathrm{A} \beta$ seeds are potent inducers of cerebral $\beta$-amyloidosis raises the possibility that such seeds may mediate the spread of $\beta$-amyloidosis in the brain. If they can be identified in vivo, soluble $\mathrm{A} \beta$ seeds in bodily fluids also could serve as early biomarkers for cerebral $\beta$-amyloidogenesis and eventually Alzheimer's disease.

\section{Introduction}

Alzheimer's disease $(\mathrm{AD})$ is an age-related neurodegenerative disorder and the most common form of senile dementia. Characteristic pathological hallmarks are proteinaceous deposits of amyloid- $\beta$ (A $\beta)$ (senile plaques) and hyperphosphorylated tau (neurofibrillary tangles), accompanied by an inflammatory response and damage to neurons and synapses (Duyckaerts et al., 2009; Holtzman et al., 2011). According to the amyloid cascade hypothesis, the misfolding and aggregation of $\mathrm{A} \beta$ is a fundamental event in the pathogenesis of AD (Hardy and Selkoe, 2002). While a wealth of studies have characterized $A \beta$ aggregation in vitro (Harper and Lansbury, 1997; Roychaudhuri et al., 2009; Du et al., 2011), much less is known about the in vivo trigger for cerebral $\beta$-amyloidosis.

\footnotetext{
Received June 17, 2011; revised Aug. 10, 2011; accepted Aug. 15, 2011

Author contributions: F.L., Y.S.E., M.S., L.C.W., and M.J. designed research; F.L., Y.S.E., and S.K.F. performed research; F.L., Y.S.E., and M.J. analyzed data; F.L., Y.S.E., M.S., L.C.W., and M.J. wrote the paper.

This work was supported by grants from the Competence Network on Degenerative Dementias (BMBF01GI0705), the Bundesministerium für Bildung und Forschung in the framework of ERA-Net NEURON (MIPROTRAN), and NIH Grant RR-00165. We thank Lisa Münter, Gerd Multhaup (Berlin), Heinke Schieb, Hans Klafki, Jens Wiltfang (Essen), Christoph Schall, Thilo Stehle (Tübingen), Ulrike Obermüller, Jörg Odenthal, Stephan Kaeser, and all the other members of our department for experimental help and comments on this manuscript.

Correspondence should be addressed to either Yvonne Eisele or Mathias Jucker at the above addresses. E-mail: yvonne.eisele@uni-tuebingen.de or mathias.jucker@uni-tuebingen.de.

DOI:10.1523/JNEUROSCI.3088-11.2011

Copyright $\odot 2011$ the authors $\quad 0270-6474 / 11 / 3114488-08 \$ 15.00 / 0$
}

We and others have shown that intracerebral injections of minute amounts of $\mathrm{A} \beta$-containing extract from $\mathrm{AD}$ brains or aged APP-transgenic (tg) mouse brains can induce $\beta$-amyloidosis and associated pathologies (activation of microglia and astrocytes; dystrophic neurites) in the brains of young APP-tg mice (Kane et al., 2000; Meyer-Luehmann et al., 2006; Eisele et al., 2009; Watts et al., 2011). $\beta$-Amyloid deposition also can be induced in APP-tg mice by intraperitoneal infusion of $A \beta$ containing brain extracts (Eisele et al., 2010), indicating that the seeds can translocate from the periphery to the brain. The probable $\beta$-amyloid-inducing factor in the brain extract has been identified as a species of aggregated A $\beta$ because (1) brain extracts from wild-type mice or pre-depositing APP-tg mice were ineffective in seeding $\beta$-amyloid; and (2) $\mathrm{A} \beta$-immunodepletion or formic acid denaturation of the extract abolished the induction of $\beta$-amyloidosis (Meyer-Luehmann et al., 2006). The finding that synthetic $\mathrm{A} \beta$ preparations fail to show robust $\beta$-amyloidinducing activity indicates that the misfolding of $\mathrm{A} \beta$ in vivo results in a different conformation and/or that brain-specific cofactors are needed for effective seeding (Meyer-Luehmann et al., 2006).

The exogenous induction of cerebral $\beta$-amyloidosis, either by intracerebral or intraperitoneal application of $\mathrm{A} \beta$ seeds, is reminiscent of the induction of prion disease in mice (Aguzzi and Rajendran, 2009; Colby and Prusiner, 2011). Prions consist of $\operatorname{PrP}^{\mathrm{Sc}}$, an abnormally folded isoform of the cellular prion protein 
$\left(\operatorname{PrP}^{c}\right)$. Upon inoculation of mice, $\operatorname{PrP}^{\mathrm{Sc}}$ can induce the templated misfolding of $\operatorname{PrP}^{\mathrm{c}}$ and thereby cause fatal neurodegeneration (Wadsworth et al., 2010). Infectious prions are multimers of $\mathrm{PrP}^{\mathrm{Sc}}$, and their size, solubility, resistance to proteinase $\mathrm{K}(\mathrm{PK})$ treatment, and ease of fragmentation govern their infectivity and neurotoxicity (Aguzzi et al., 2007; Collinge and Clarke, 2007).

The objective of the present study was to further characterize the $\beta$-amyloid-inducing factor in the $\mathrm{A} \beta$-containing extract from aged APP-tg mouse brains. Guided by the prion findings, we have tested the PK resistance, solubility, and fragmentation of the amyloidogenic seeds. Our results bolster the assumption that the $\beta$-amyloid-inducing factor is $\mathrm{A} \beta$, and indicate that, rather than consisting of a single type of multimer, $\beta$-amyloid seeds comprise a range of $\mathrm{A} \beta$ aggregates of various sizes and $\mathrm{PK}$-sensitivities.

\section{Materials and Methods}

Mice. For all experiments, 3- to 4 month-old male or female APP23 transgenic mice were used (Sturchler-Pierrat et al., 1997). The mice have been backcrossed with C57BL/6J mice for 20 generations (C57BL/6J$\operatorname{Tg}\left(\right.$ Thy1-APP $\left.\left.{ }_{\text {K670N;M671L }}\right) 23\right)$. APP23 mice currently bred at the Hertie Institute for Clinical Brain Research first develop individual $\beta$-amyloid plaques in the neocortex at 7 months of age. In the hippocampus, $\beta$-amyloid deposition starts at $8-10$ months of age (females $8-9$ months; males 9-10 months). All mice were kept under specific pathogen-free conditions. The experimental procedures were undertaken in accordance with the veterinary office regulations of Baden-Württemberg (Germany) and approved by the local Animal Care and Use Committees.

Brain tissue extracts. Brain extracts were derived from aged (22-28 months old) $\beta$-amyloid-depositing male or female APP23 transgenic mice and from age-matched nontransgenic mice. After removal of the cerebellum and lower brainstem, the forebrain was immediately fresh frozen on dry ice and stored at $-80^{\circ} \mathrm{C}$ until use. Tissue was then homogenized (Ultra Turrax T8, IKA-Werke) at $10 \%(\mathrm{w} / \mathrm{v})$ in sterile PBS (Lonza), vortexed, sonicated three times for $5 \mathrm{~s}$ (LabSonic, B. Braun Biotech International; 0.5-mm-diameter sonotrode, cycle 1, amplitude $80 \%$ ), and centrifuged at $3000 \times g$ for $5 \mathrm{~min}$ as previously described (Meyer-Luehmann et al., 2006; Eisele et al., 2009). The supernatant was aliquoted and immediately frozen. For all experiments, the $10 \%(\mathrm{w} / \mathrm{v})$ extract was used unless otherwise stated.

Synthetic $A \beta$ preparations. $\mathrm{A} \beta_{1-40}$ and $\mathrm{A} \beta_{1-42}$ (American Peptide) were dissolved at equimolar concentrations in PBS to reach a final concentration of $100 \mu \mathrm{M}$ total $\mathrm{A} \beta$. To generate fibrils, the peptides were incubated on a rotator for $5 \mathrm{~d}$ at $37^{\circ} \mathrm{C}$ as previously described (MeyerLuehmann et al., 2006). Fibrils were stored at $-80^{\circ} \mathrm{C}$ until use.

Proteinase $K$ treatment of the brain extract and synthetic $A \beta$. Brain extracts and synthetic $A \beta$ preparations were thawed on ice and subsequently treated with $50 \mu \mathrm{g} / \mathrm{ml}$ PK (Roche Diagnostics) for up to $2 \mathrm{~h}$ at $37^{\circ} \mathrm{C}$. After $30 \mathrm{~min}, 1 \mathrm{~h}$, or $2 \mathrm{~h}$, samples were boiled for $5 \mathrm{~min}$ at $95^{\circ} \mathrm{C}$ to heat-inactivate the PK.

Ultracentrifugation of the brain extract. Brain extracts were thawed on ice and centrifuged in a Beckman Centrifuge at $100,000 \times g$ for $1 \mathrm{~h}$ at $4^{\circ} \mathrm{C}$ in Protein LoBind Tubes (Eppendorf). Supernatant was transferred to a new tube and the pellet was resuspended in sterile PBS to obtain the same volume as the supernatant. Samples were stored on ice until use.

Fragmentation of the brain extract. Brain extracts [10\% (w/v) in PBS; $3000 \times g$ supernatant] were thawed on ice and sonicated with a LabSonic (B. Braun Biotech International) three times for $20 \mathrm{~s} \mathrm{(0.5-mm-diameter}$ sonotrode, cycle 1 , amplitude $80 \%$ ).

$A \beta$ quantification of the extract by electrochemiluminescence-linked immunoassay. $\mathrm{A} \beta$ levels $\left(\mathrm{A} \beta_{x-38}, \mathrm{~A} \beta_{x-40}\right.$, and $\left.\mathrm{A} \beta_{x-42}\right)$ in extracts were determined with an electrochemiluminescence-linked immunoassay using the MSD 96-well MULTI-SPOT Human (6E10) A $\beta$ Triplex Assay (Meso Scale Discovery). To this end, the extracts were first treated with formic acid (final concentration: 70\%) (Sigma). Samples were sonicated for $30 \mathrm{~s}$ on ice and centrifuged at $25,000 \times g$ for $1 \mathrm{~h}$ at $4^{\circ} \mathrm{C}$. Supernatants were equilibrated in neutralization buffer $\left(1 \mathrm{M}\right.$ Tris base, $0.5 \mathrm{M} \mathrm{Na}_{2} \mathrm{HPO}_{4}$, $\left.0.05 \% \mathrm{NaN}_{3}\right)$. The $100,000 \times g$ supernatant was measured directly. $\mathrm{A} \beta$ detection was further conducted according to the manufacturer's instructions. In brief, 96-well plates prespotted with capture antibodies against $\mathrm{A} \beta_{x-38}, \mathrm{~A} \beta_{x-40}, \mathrm{~A} \beta_{x-42}$, and bovine serum albumin were blocked for $1 \mathrm{~h}$ with $1 \%$ Blocker A solution and then washed three times with $1 \times$ Tris buffer. In a second step, samples were diluted 1:100 in 1\% Blocker A solution, except supernatant of ultracentrifugation, and coincubated with the SULFO-TAG 6E10 detection antibody solution on the plate for $2 \mathrm{~h}$. After washing, MSD Read Buffer T was added and the plate was read immediately on a Sector Imager 6000. Data analysis used MSD DISCOVERY WORKBENCH software 2.0. For total $\mathrm{A} \beta, \mathrm{A} \beta_{x-38}, \mathrm{~A} \beta_{x-40}$, and $\mathrm{A} \beta_{x-42}$ were combined.

Total protein quantification. Total protein of the brain extract was quantified with a microplate bicinchoninic acid (BCA) assay (Pierce Biotechnology). Samples were measured on an ELISA plate reader (Mithras, Berthold Technologies).

SDS-PAGE and silver staining of proteins. Brain extracts and synthetic $\mathrm{A} \beta$ preparations were analyzed on NuPage Bis-Tris mini gels using $\mathrm{Nu}$ Page LDS sample buffer and MES running buffer (Invitrogen). To stain for total protein, silver staining was performed according to a previously established protocol (Nesterenko et al., 1994) with the following modifications. Gels were fixed with a solution of $50 \%$ acetone, $1 \%$ trichloroacetic acid (TCA) and $0.015 \%$ formaldehyde (HCHO) for $5 \mathrm{~min}$, washed three times with double-distilled water $\left(\mathrm{ddH}_{2} \mathrm{O}\right)$, incubated again with $\mathrm{ddH}_{2} \mathrm{O}$ for $5 \mathrm{~min}$ and washed again thrice. For pretreatment, gels were incubated in pure acetone for $5 \mathrm{~min}$ and afterward $1 \mathrm{~min}$ in $1.4 \mathrm{~mm}$ dithionite solution. After washing with $\mathrm{ddH}_{2} \mathrm{O}$, the staining solution ( $15.7 \mathrm{~mm}$ silver nitrate in $\mathrm{ddH}_{2} \mathrm{O}$ with $0.18 \% \mathrm{HCOH}$ ) was added and incubated for $8 \mathrm{~min}$. This step was followed by incubation in a developing solution ( $70 \mathrm{~mm}$ soda-decahydrate, $0.015 \% \mathrm{HCHO}$, and $0.004 \%$ sodium thiosulfate) and the staining was stopped afterward with $3 \%$ glacial acetic acid. After washing with $\mathrm{ddH}_{2} \mathrm{O}$, the gel was incubated in a gel-drying solution ( $5 \%$ glycerol and $30 \%$ methanol in $\mathrm{dd}_{2} \mathrm{O}$ ) for $30 \mathrm{~min}$. Staining of the gel was documented with a scanner, and afterward the gel was dried with a Gel Dryer (Bio-Rad).

Western blot analysis. Brain extracts and synthetic $\mathrm{A} \beta$ preparations were analyzed on NuPage Bis-Tris mini gels using NuPage LDS sample buffer and MES running buffer (Invitrogen). For Western blotting, samples were wet-blotted onto a nitrocellulose membrane, probed with 6E10 antibody (Covance Research Products) and visualized with chemiluminescence using SuperSignal West Pico (Thermo Scientific). Densitometric values of band intensities were analyzed using the public domain software ImageJ, version 1.34 (http://imagej.nih.gov/ij/).

Stereotactic injection of brain extracts. APP23 host mice were anesthetized with a mixture of ketamine ( $100 \mathrm{mg} / \mathrm{kg}$ body weight) and xylazine (10 mg/kg body weight) in saline. Bilateral stereotactic injections of 2.5 $\mu \mathrm{l}$ brain extract were made with a Hamilton syringe into the hippocampus (AP $-2.5 \mathrm{~mm}, \mathrm{~L} \pm 2.0 \mathrm{~mm}, \mathrm{DV}-1.8 \mathrm{~mm}$ ). Injection speed was 1.0 $\mu \mathrm{l} / \mathrm{min}$ and the needle was kept in place for an additional $2 \mathrm{~min}$ before it was slowly withdrawn. The surgical area was cleaned with sterile saline, the incision was sutured, and the mice were monitored until recovery from anesthesia.

Histology and immunohistochemistry. Brains were removed and immersion fixed for $48 \mathrm{~h}$ in $4 \%$ paraformaldehyde in PBS, then cryoprotected in $30 \%$ sucrose in PBS for an additional $2 \mathrm{~d}$. After freezing, serial, $25-\mu \mathrm{m}$-thick coronal sections were cut through the brains using a freezing-sliding microtome. The sections were collected in $0.1 \mathrm{M}$ Trisbuffered saline, $\mathrm{pH}$ 7.4, and stained immunohistochemically according to previously published protocols (Stalder et al., 2005). Polyclonal antibody CN3 (Eisele et al., 2010) was used for immunostaining of $\mathrm{A} \beta$. Adjacent sections were stained with Congo red according to standard protocols and viewed under cross-polarized light. The following additional antibodies were used: rabbit polyclonal antibody against cow glial fibrillary acidic protein (GFAP) (Dako); rabbit polyclonal antibody against ionized calcium binding adapter molecule 1 (Iba1) (Wako); and rabbit polyclonal antibody A4CT against APP (Calhoun et al., 1999) (gift from K. Beyreuther, Netzwerk Alternsforschung, Ruprecht-KarlsUniversität, Heidelberg, Germany).

Quantification of total $A \beta$ load and Congo red-positive $A \beta$ deposits. $A \beta$ load was quantified on an $A \beta$-immunostained set of every 12 th system- 

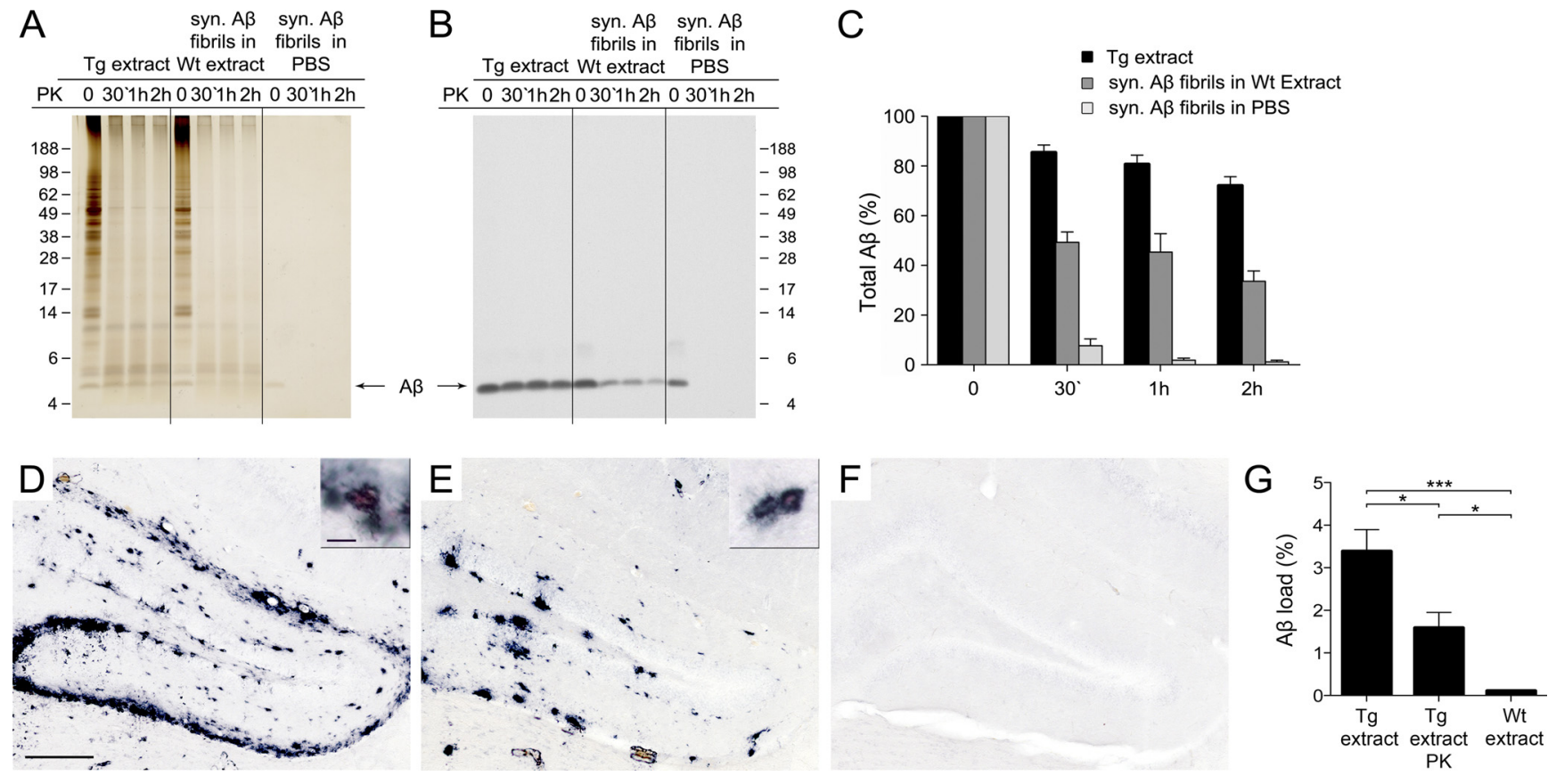

Figure 1. The $\beta$-amyloid-inducing activity is partly proteinase K-resistant. Brain extracts from an aged APP23 tg mouse (Tg extract), an aged non-tg mouse (Wt extract) spiked with synthetic A $\beta$ fibrils (syn. $A \beta$ fibrils in Wt extract; $10 \mu \mathrm{m} \mathrm{A} \beta$ ), and synthetic $A \beta$ fibrils in PBS (syn. A $\beta$ fibrils in PBS; $10 \mu \mathrm{m}$ ) were treated with $50 \mu \mathrm{g} / \mathrm{ml} \mathrm{PK}$ for $0 \mathrm{~min}, 30 \mathrm{~min}, 1 \mathrm{~h}$, or $2 \mathrm{~h}$ at $37^{\circ} \mathrm{C}$. $A$, Silver staining of a $12 \%$ Bis-Tris NuPage gel for total protein reveals the digestion of the majority of proteins in the brain extracts and of synthetic $A \beta$ fibrils already after 30 min PK treatment. $\boldsymbol{B}$, Immunoblot analysis with an antibody specific to human $A \beta$ (6E10) shows that $A \beta$ in the Tg extract is largely PK resistant for up to $2 \mathrm{~h}$. $A \beta$ in the spiked Wt extract revealed some, but significantly less PK resistance, whereas synthetic $A \beta$ fibrils in PBS were almost completely digested by the PK treatment. C, Densitometric quantification of $A \beta$-immunoblots after PK treatment of five Tg extracts (each from a different animal) and three independent synthetic $A \beta$ fibril preparations are shown. Each preparation was tested at least three times and the mean was taken. $A \beta$ concentration at time point 0 was designated as $100 \%$. Indicated is the mean \pm SEM. Repeated-measures two-way ANOVA revealed a significant difference between the groups $\left(F_{(2,34)}=112.2\right)$. Multiple Bonferroni posthoc tests showed significances after PK digestion for all group comparisons, $p<0.001$. D-F, In vivo seeding activity of brain extracts with or without PK treatment (50 $\mu \mathrm{g} / \mathrm{ml} \mathrm{PK}$ for $30 \mathrm{~min})$ was tested by intrahippocampal injections into young, pre-depositing 4-month-old APP23 mice. Brains were immunohistochemically analyzed for A $\beta$ deposition 5 months later. Shown is the dentate gyrus of the hippocampus, which revealed robust $\beta$-amyloid induction by the $\operatorname{Tg}$ extract $(\boldsymbol{D})$ and the PK-treated $\operatorname{Tg}$ extract $(\boldsymbol{E})$, but not with Wt extract $(\boldsymbol{F})$. Note that extracts were boiled before injection to deactivate residual PK activity. The small insert shows double staining for $A \beta$ immunoreactivity and Congo red binding of the induced $\beta$-amyloid in an adjacent section. Scale bars: $200 \mu \mathrm{m}$ and 20 $\mu \mathrm{m}$. G, Stereological quantification of A $\beta$ load in the hippocampus. Although PK treatment reduced the $\beta$-amyloid induction, the PK-resistant Tg material still showed potent seeding activity compared to the Wt extract $\left(n=5-6\right.$ mice per group; mean \pm SEM: ANOVA followed by Bonferroni post hoc tests revealed a significant difference between the extracts $\left(F_{(2,14)}=18.95\right.$, ${ }^{* * *} p<$ $\left.0.001 ;{ }^{*} p<0.05\right)$. Note that neither PK-treated nor untreated Wt extract induced any amyloid, and therefore these groups were combined.

atically sampled, serial, coronal section throughout the entire hippocampus. Researchers who were blinded to the inoculation groups performed the analysis. Stereological analysis of $\mathrm{CN} 3$-positive staining was performed using a microscope equipped with a motorized $x-y-z$ stage coupled to a video-microscopy system and the Stereo Investigator software (MicroBrightField) as previously described (Bondolfi et al., 2002). The $\beta$-amyloid load (percentage) was determined by calculating the areal fraction occupied by $\mathrm{CN} 3$-positive immunostaining in two-dimensional sectors at a single focal plane $(20 \times / 0.45$ objective). The percentage of $A \beta$ deposits that were also Congo red positive was determined manually on an adjacent set of systematically sampled sections that were double stained by the anti-A $\beta$ antibody and Congo red. Quantification was performed using a $20 \times$ objective and a Zeiss Axioskop 2 microscope (Zeiss).

\section{Results}

The $\boldsymbol{\beta}$-amyloid-inducing factor is partially $\mathrm{PK}$ resistant

Brain extracts from aged APP23 transgenic mice (Tg extract) and preparations of synthetic $\mathrm{A} \beta$ fibrils in PBS or spiked into brain extract from aged nontransgenic (wild-type) mice (Wt extract) were incubated with $50 \mu \mathrm{g}$ of $\mathrm{PK} / \mathrm{ml}$ for up to $2 \mathrm{~h}$. Subsequent $\mathrm{A} \beta$ immunoblotting revealed that $\mathrm{A} \beta$ in the Tg extract was to a high degree PK resistant (80\% remaining after 30 min PK treatment; $70 \%$ remaining after $2 \mathrm{~h}$ PK treatment), whereas synthetic $\mathrm{A} \beta$ fibrils were almost completely digested after $30 \mathrm{~min}$ (Fig. $1 A-C$ ). The spiking of the synthetic $\mathrm{A} \beta$ fibrils into $\mathrm{Wt}$ extract made the fibrils more PK resistant (50\% remaining after $30 \mathrm{~min}$ PK treatment; $35 \%$ remaining after $2 \mathrm{~h}$ PK treatment), although they were still significantly less resistant than were the $\mathrm{A} \beta$ aggregates in the Tg extract (Fig. 1 $A-C$ ).

To test whether PK-treated Tg extracts harbor $\beta$-amyloidinducing activity in vivo, Tg extracts with and without $\mathrm{PK}$ treatment were injected into the hippocampus of 4-month-old pre-depositing APP23 mice and compared with the injection of Wt extracts (Fig. $1 D-G$ ). Inactivation of PK was achieved by boiling the samples (including the controls) before injection. Boiling has been found to reduce, but not abolish, the $\beta$-amyloidinducing activity of the brain extracts (Meyer-Luehmann et al., 2006). Therefore, to optimize the seeding signal, an incubation time of 5 months was chosen. Immunohistochemical analysis revealed robust $\beta$-amyloid deposition in the hippocampus of mice receiving either the Tg extract or the PK-treated Tg extract, whereas $\beta$-amyloid was not induced by the Wt extracts (Fig. $1 D$ $F)$; i.e., the effect of the Wt extract was not different from that of the PBS injection (A $\beta$ load: $0.06 \pm 0.03 \%$ vs $0.03 \pm 0.01 \%$; $n=$ $5-6$ per group, mean \pm SEM, $\left.t_{(9)}=1.893 ; p>0.05\right) . \beta$ amyloid induced by the PK-treated Tg extract was both congophilic and diffuse $(51.1 \pm 8.1 \%$ of the $\mathrm{A} \beta$ deposits had a detectable Congo red-positive core). All congophilic $\beta$-amyloid plaques were surrounded by intensely stained hypertrophic GFAP-positive astrocytes, activated Ibal-positive microglia, as well as APP-positive dystrophic neurites, as previously described (Meyer-Luehmann et al., 2006). Quantification of the induced $\beta$-amyloid load indicated, 

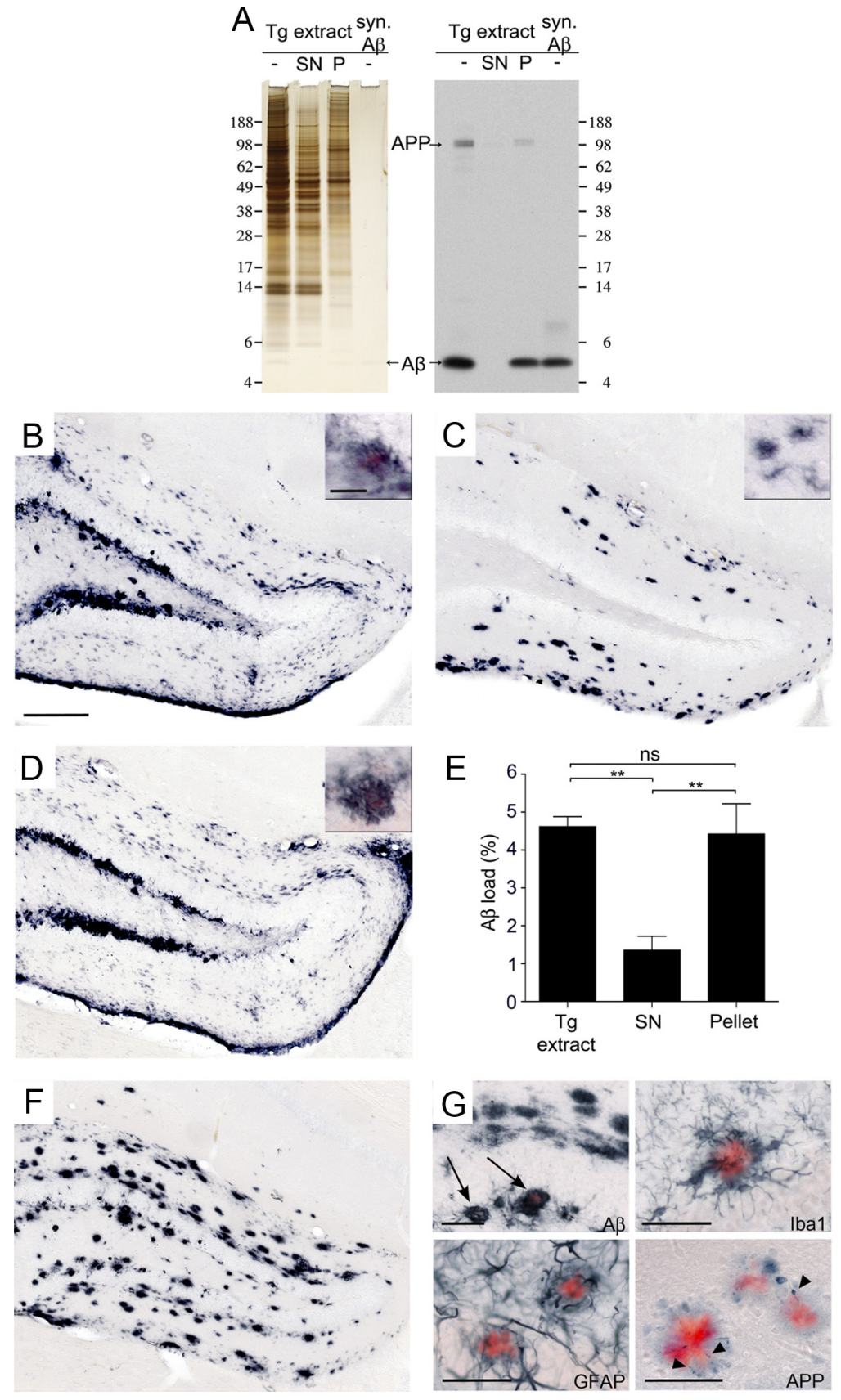

Figure 2. The $\beta$-amyloid-inducing activity is partly soluble. $\boldsymbol{A}$, Brain extracts (10\%,w/v) from aged APP23 mice (Tg extract) were subjected to $100,000 \times$ gultracentrifugation $\left(1 \mathrm{~h}, 4^{\circ} \mathrm{C}\right)$. Left panel, Silver staining of a $12 \%$ Bis-Tris gel shows somewhat less protein in the pellet fraction (P) compared to the supernatant ( $\mathrm{SN}$ ) fraction (this was confirmed by total protein measurements revealing $\sim 60 \%$ of the protein in the supernatant and $40 \%$ in the pellet, see results). Right panel, Immunoblotting for human $A \beta$ (antibody 6 E10) using $12 \%$ Bis-Tris gels reveals that most $A \beta$ is retained in the pellet fraction. $A \beta$ in the supernatant was below the level of detection by this immunoblot, but was estimated to be $<0.05 \%$ of total $A \beta$ concentration in the original Tg extract using ELISA (see Table 1). Loading control: synthetic $A \beta, 15 \mathrm{ng} /$ lane. $\boldsymbol{B}-\boldsymbol{D}$, In vivo seeding activity of the supernatant and pellet fractions was tested by intrahippocampal injections into young, pre-depositing 4-month-old APP23 mice. Brains were immunohistochemically analyzed for $A \beta$ deposition 4 months after injection. Shown is the dentate gyrus of the hippocampus. While the $\mathrm{Tg}$ extract $(\boldsymbol{B})$ induced robust $A \beta$ deposition, the $S N$ fraction $(\boldsymbol{C}$ induced largely diffuse Congo red-negative $A \beta$ deposits. $A \beta$ deposition induced by the pellet fraction $(\boldsymbol{D})$ is similar to that induced by the Tg extract. The small insert shows double staining of $A \beta$ and Congo red in seeded $\beta$-amyloid in an adjacent section. Note that the $\beta$-amyloid-induction by the $\mathrm{SN}$ was largely Congo red negative after this 4 month incubation period, but was partly Congo red positiveafter a 6 month incubation (see $G$ below). $\boldsymbol{E}$,Stereological quantification of $A \beta$ load in the hippocampus 4 months after injection ( $n=5$ mice per group; mean \pm SEM; ANOVA followed by Bonferroni posthoctest $\left(F_{(2,13)}=11.93 ; * * p<0.01 ; n\right.$. ., not significant). Note that an additive effect of the $\beta$-amyloid induction by the SN and P fractions cannot be assumed (Meyer-Luehmann et al., 2006). $\boldsymbol{F}, \beta$-Amyloid induction by the SN fraction 6 months after injection. G, The majority of the $S N$ fraction-induced $\beta$-amyloid-deposits at 6 months after injection were still Congo red negative; however, a subset of the induced deposits were congophilic (arrow) and surrounded by activated, darkly stained Iba-1-positive microglia, hypertrophic GFAP-positive astrocytes, and APP-positive dystrophic boutons and neurites (arrowheads). Shown are sections adjacent to $\boldsymbol{F}$. Scale bars: $200 \mu \mathrm{m}, 20 \mu \mathrm{m}(\boldsymbol{B}-\boldsymbol{D}, \boldsymbol{F})$, and $50 \mu \mathrm{m}(\boldsymbol{G})$. however, that the PK-treated Tg extracts yielded only $55 \%$ of the $\beta$-amyloidinducing activity of the $\mathrm{Tg}$ extract without PK treatment (Fig. $1 G$ ), suggesting a partial digestion of the $\beta$-amyloid-inducing activity by PK. Histological analysis of the brains $1 \mathrm{~d}$ after injection of the PK-treated Tg extract revealed no $\mathrm{A} \beta$ deposits, ruling out the possibility that the induced $A \beta$ deposition represents the injected material itself $(n=3$; data not shown), consistent with previous studies (Meyer-Luehmann et al., 2006; Eisele et al., 2009).

\section{The $\boldsymbol{\beta}$-amyloid-inducing factor is partially soluble}

Tg extract was ultracentrifuged $(100,000 \times g$ for $1 \mathrm{~h}$ at $4^{\circ} \mathrm{C}$ ) and the supernatant and pellet fractions were subsequently assessed for total protein content and $\mathrm{A} \beta$ levels. Measurements of total protein concentration (by BCA assay) revealed $3.6 \pm 0.2 \mu \mathrm{g} / \mu \mathrm{l}$ and $2.8 \pm 0.3 \mu \mathrm{g} / \mu \mathrm{l}$ protein in the supernatant and in the pellet fraction, corresponding to $\sim 60 \%$ and $40 \%$ of total protein of the original extract, respectively. This is consistent with the silver staining of acrylamide gels (Fig. $2 A$ ). In contrast, $A \beta$ immunoblotting and $A \beta$-ELISA revealed that the great majority ( $>99.9 \%)$ of $A \beta$ was in the pellet fraction (Fig. 2A, Table 1).

To investigate the $\beta$-amyloid-inducing activity of these fractions, 3- to 4-monthold, pre-depositing APP23 mice were given intracerebral injections of the material. Histological analysis was performed 4 months later (Fig. $2 B-D$ ). Both the supernatant and pellet fractions induced $\beta$-amyloid deposition. The $\beta$-amyloid induction by the pellet fraction achieved $95 \%$ of the activity observed with unfractionated, total Tg extract. Strikingly, the supernatant induced almost $30 \%$ of the $\beta$-amyloid load observed with the total $\mathrm{Tg}$ extract (Fig. 2E). Given that this fraction harbors $<0.05 \%$ of the $\mathrm{A} \beta$ in the total $\mathrm{Tg}$ extract, these observations indicate a very high seeding activity of the $100,000 \times g$ soluble $\mathrm{A} \beta$ assemblies in the brain extract (Table $1)$. The $\beta$-amyloid deposits induced by the pellet fraction were morphologically similar to those in the original Tg extract, while the $\beta$-amyloid induced by the supernatant was mostly diffuse and Congo red-negative (only $2.4 \pm 1.0 \%$ of the compact $\mathrm{A} \beta$ deposits had a Congo red-positive core in comparison to $39.8 \pm 6.5 \%$ with the unfractionated, total extract) after the 4 month incubation period (Fig. 2C). After a 6 month incubation period, however, the compact deposits induced by the supernatant fraction also were increasingly Congo red positive $(29.8 \pm 1.2 \%$ ) (Fig. $2 F)$. Again, 
all of the Congo red-positive $\mathrm{A} \beta$ deposits were accompanied by cytopathologic changes, i.e., activation of microglia and astrocytes, as well as dystrophic neurites (Fig. $2 G$ ), all identical in appearance to those induced by the total extract and in normal aged APP23 mice (Meyer-Luehmann et al., 2006).

The soluble $\beta$-amyloid-inducing factor is largely PK sensitive Next we assessed the PK-sensitivity of the soluble $\beta$-amyloidinducing fraction (Fig. 3). Results demonstrated that $<5 \%$ of the $\mathrm{A} \beta$ in the $100,000 \times g$ supernatant fraction was resistant to 30 min PK treatment, while the original $\mathrm{Tg}$ extract again revealed $80 \%$ PK resistance (Fig. $3 A, B$ ). The pellet fraction resulting from ultracentrifugation showed PK resistance similar to that of the untreated $\mathrm{Tg}$ extract (data not shown). The in vivo $\beta$-amyloid-inducing activity of the PKdigested supernatant fraction was then evaluated by intracerebral injections into 3-month-old pre-depositing APP23 mice, and compared with the activity of the undigested supernatant fraction 6 months after injection. Inactivation of PK was again achieved by boiling the samples (including the controls) before injection. Results revealed the expected $\beta$-amyloid induction by the supernatant fraction, whereas PK treatment almost completely abolished the $\beta$-amyloid-inducing activity of this fraction (Fig. $3 C-E$ ), suggesting that the potent, $\beta$-amyloidinducing soluble $A \beta$ assemblies are PK sensitive.

\section{Extended sonication increases \\ $\boldsymbol{\beta}$-amyloid-inducing activity}

To determine whether fragmentation of aggregates can augment the seeding capacity of brain extracts, the impact of extended sonication on the $\beta$-amyloidinducing activity of the Tg extracts was assessed. Immunoblot analysis of the original (briefly sonicated) $\mathrm{Tg}$ extract and $\mathrm{Tg}$ extract with extended sonication revealed no change in total $\mathrm{A} \beta$ concentration (Fig. $4 A$ ). However, ultracentrifugation of the extracts revealed a higher amount of soluble $A \beta$ in the supernatant of the Tg extract that had undergone extended sonication, suggesting the breakage of insoluble $A \beta$ assemblies into smaller, 100,000 $\times g$ soluble units (Fig. $4 A$ ). The additional $\mathrm{A} \beta$ released into the supernatant fraction after extended sonication showed PK sensitivity similar to that of the $A \beta$ in the supernatant of the untreated Tg extract (data not shown).

To test the $\beta$-amyloid-inducing activity of the Tg extract with and without extended sonication, extracts were injected intracerebrally into 4-month-old APP23 mice, and the brains of the injected animals were analyzed 4 months later. $A \beta$ immunostaining revealed increased induction of $\beta$-amyloid deposits in the mice injected with the extra-sonicated brain extract compared to the mice injected with the original seeding extract (Fig. $4 B-D$ ). Morphologically, the original seeding extract induced a more filamentous and dense pattern of $\beta$-amyloid aggregation, $\left.4.713 ;{ }^{* *} p<0.01\right)$.
Table 1. Ultracentrifugation of the Tg extract

\begin{tabular}{lll}
\hline & $\begin{array}{l}\text { Total } \mathrm{A} \beta^{a}[\mathrm{ng} / \mu \mathrm{l}] \\
\text { (relative amount to Tg extract) }\end{array}$ & $\begin{array}{l}\beta \text {-amyloid load }{ }^{b}[\%] \\
\text { (relative amyloid load to Tg extract) }\end{array}$ \\
\hline Tg extract & $14.838 \pm 0.308(1)$ & $4.62 \pm 0.26(1)$ \\
Supernatant & $0.005 \pm 0.003(0.004)$ & $1.35 \pm 0.37(0.29)$ \\
Pellet & $14.885 \pm 1.181(1)$ & $4.42 \pm 0.80(0.95)$ \\
\hline
\end{tabular}

${ }^{a_{E} L L S A}$ measurements were done with three different Tg extracts. Mean \pm SEM is indicated. Note that $2.5 \mu$ l of each fraction were injected.

${ }^{b}$ Stereological quantification of induced $\beta$-amyloid. Mean \pm SEM is indicated. Data are taken from Fig. $2 E$. Note that $\beta$-amyloid induction is not linear to the $A \beta$ concentration in the extract (see Meyer-Luehmann et al., 2006). Thus, an additive effect of $\beta$-amyloid induction of the two fractions cannot be assumed.
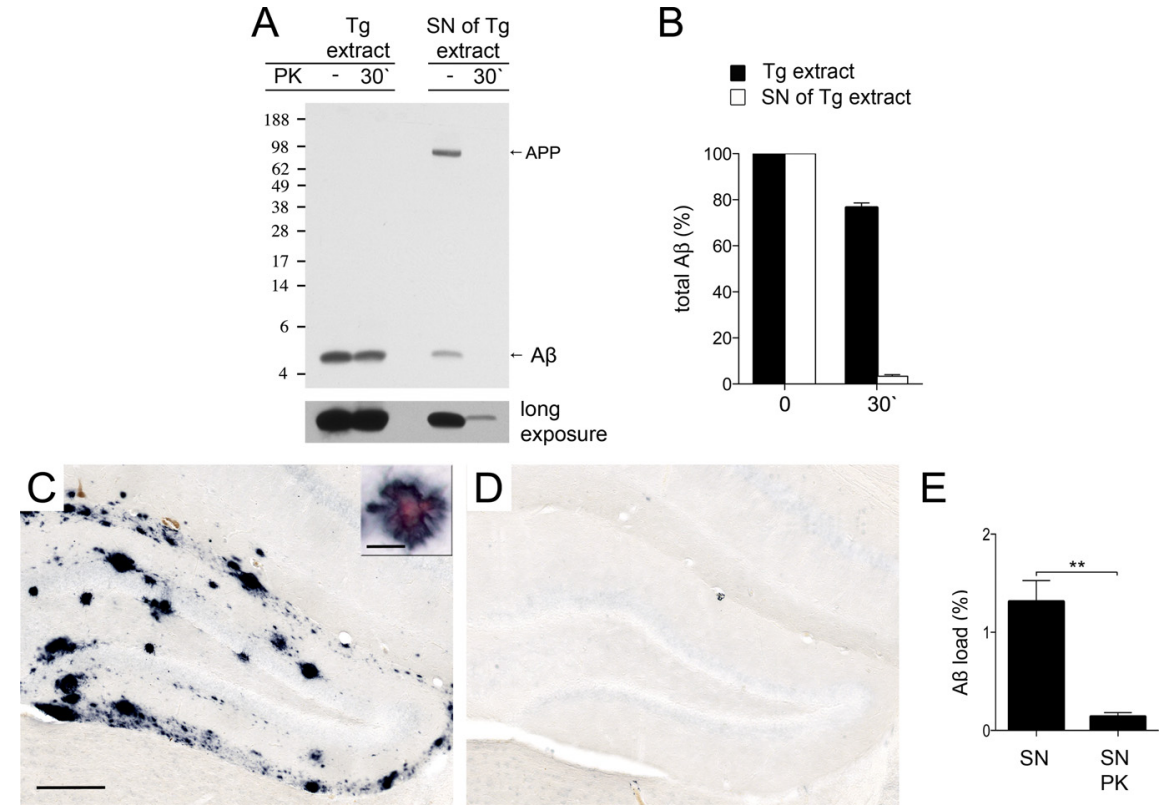

Figure 3. The soluble $\beta$-amyloid-inducing activity is mostly proteinase $K$ sensitive. $A$, Brain extracts $(10 \%, w / v)$ from aged APP23 mice (Tg extract) and the $100,000 \times g$ supernatant $(S N)$ of the $\mathrm{Tg}$ extract (ultracentrifugation, $1 \mathrm{~h}, 4^{\circ} \mathrm{C}$ ) were treated with $50 \mu \mathrm{g} \mathrm{PK} / \mathrm{ml}$ for $30 \mathrm{~min}$ at $37^{\circ} \mathrm{C}$. Immunoblotting for human A $\beta$ (antibody 6 E10) using $12 \%$ Bis-Tris gels reveals the expected PK resistance of the Tg extract. In contrast, only a minor fraction of the SN was not cleaved by PK (see long exposure). Note that the Tg tively. Also note that there is an empty lane between the two Tg extract lanes and the two lanes with the SN. $\boldsymbol{B}$, Densitometric analysis of $A \beta$ immunoblots after PK treatment [ $4 \mathrm{Tg}$ extracts (each from a different animal) and the corresponding 100,000 $\times g$ 政 analyzed for $A \beta$-deposition 6 months later. Shown is the dentate gyrus of the hippocampus. SN of Tg brain extract was boiled for 5 min at $95^{\circ} \mathrm{C}(\boldsymbol{C})$. The small inset shows double labeling of $\mathrm{A} \beta$ immunoreactivity and Congo red binding of the induced $\beta$-amyloid quantification of $A \beta$ load in the hippocampus. PK treatment of the $100,000 \times g$ supernatant of Tg brain extract diminished the seeding activity. $t$ test revealed a significant difference between the two groups $\left(n=4-5\right.$ mice per group, mean $\pm S E M, t_{(7)}=$

whereas the deposits induced by the extra-sonicated seeding extract appeared smaller and more punctate. In both groups, a subset of the induced $\mathrm{A} \beta$ deposits were Congo red positive (Fig. $4 B, C)$.

\section{Discussion}

Converging experimental data implicate corruptive protein templating in the induction and spread of proteinaceous lesions in a number of neurodegenerative diseases (Walker et al., 2006; Aguzzi and Rajendran, 2009; Colby and Prusiner, 2011). Pathologic similarities with prion disease suggest that these other disorders, though not known to be infectious, could involve the prion-like propagation of proteopathic seeds (Jucker and 

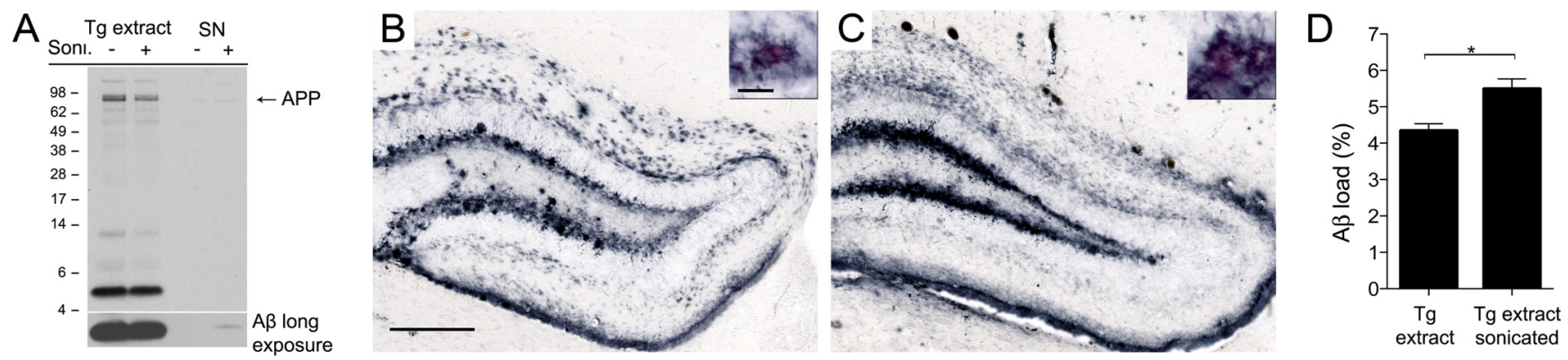

Figure 4. Extended sonication increases $\beta$-amyloid-inducing activity. Brain extracts [10\% (w/v)] from aged APP23 mice (Tg extract) were subjected to additional sonication ( $3 \times 20$ s). $A$, Immunoblot analysis with an antibody specific to human $A \beta$ reveals no change in total $A \beta$ between the original Tg extract $(-)$ and the extract with extended sonication $(+)$. However, more $A \beta$ was found in the supernatant (SN) of the extra-sonicated extract after ultracentrifugation $(100,000 \times g ; 1 \mathrm{~h})$ (long exposure). $\boldsymbol{B}, \boldsymbol{C}$, In vivo seeding activity of the original and extra-sonicated extracts was tested by intrahippocampal injections into young, pre-depositing APP23 mice. Brains were immunohistochemically analyzed for A $\beta$ deposition 4 months after injection. Shown is the dentate gyrus of the hippocampus. Injection of original $\operatorname{Tg}$ extract $(\boldsymbol{B})$ induced robust congophilic $A \beta$ deposition with a filamentous and dense pattern, while $A \beta$ induction with the extra-sonicated $\mathrm{Tg}$ extract generated more punctate and small deposits (C). The inset shows double labeling of $A \beta$ immunoreactivity and Congo red binding of the induced $\beta$-amyloid. Scale bars: $200 \mu \mathrm{m}$ and $20 \mu \mathrm{m}$. $\boldsymbol{D}$, Stereological quantification of A $\beta$ load in the hippocampus revealed a significant increase in $\beta$-amyloid induction by extended sonication $\left(n=5-6\right.$ mice per group; mean \pm SEM, $t_{(9)}=3.188$; $\left.{ }^{*} p<0.05\right)$.

Walker, 2011). While it is now evident that the aggregation of $\mathrm{A} \beta$ can be exogenously induced in vivo by brain extracts containing aggregated A $\beta$ (Kane et al., 2000; Meyer-Luehmann et al., 2006; Eisele et al., 2009, 2010; Watts et al., 2011), the seeds themselves have not been rigorously characterized. The present findings, together with previous work (Meyer-Luehmann et al., 2006), indicate that the $\beta$-amyloid-inducing factor in brain extracts from aged, APP-tg mice consists of a range of aggregated $A \beta$ species of different sizes and of various sensitivities to $P K$ digestion.

We previously found that synthetic $A \beta$ fibrils_-in PBS or mixed with wild-type brain extract- do not effectively seed $A \beta$ deposition in vivo (Meyer-Luehmann et al., 2006). Our present results reveal that aggregated $\mathrm{A} \beta$ from $\beta$-amyloid-laden brains is more PK resistant than are synthetic $A \beta$ fibrils. Because the amino acid sequence is the same, this finding indicates that $\mathrm{A} \beta$ fibrils in vivo either assume a multidimensional conformation that confers PK resistance compared to that of synthetic $\mathrm{A} \beta$ fibrils, or that posttranslational modifications and/or auxiliary factors in the brain inhibit the interaction of proteinase $\mathrm{K}$ with $\mathrm{A} \beta$. Conformation has been shown to influence the resistance of $A \beta$ to proteases, presumably by determining the accessibility of putative cleavage sites (Nordstedt et al., 1994), and differences in the structural properties of brain-derived $A \beta$ fibrils and synthetic $A \beta$ fibrils have been reported (Paravastu et al., 2009). In addition to these conformational differences, cofactors in the brain may protect $\mathrm{A} \beta$ fibrils from protease cleavage (Tennent et al., 1995; Söderberg et al., 2005), which may explain our finding of increased PK resistance of synthetic $A \beta$ fibrils that are mixed with wild-type brain extract. Alternatively, the increased PK resistance could be an indirect effect of the increase in total protein when synthetic $\mathrm{A} \beta$ is mixed with wild-type brain extract.

Misfolded proteins with increased protease resistance may escape proteolytic degradation and become proteopathic seeds (Lansbury, 1997; Powers et al., 2009). However, PK resistant A $\beta$ seeds are not the sole inductive species in our assay. PK-treated extracts induced $\beta$-amyloid deposition at a magnitude of only $\sim 55 \%$ of that of untreated extract (Fig. 1), arguing that PKsensitive seeds must exist, and that they are highly efficient $\beta$-amyloid-inducing agents. This conclusion is supported by our ultracentrifugation experiments. Although $<0.05 \%$ of the $\mathrm{A} \beta$ was in the $100,000 \times g$ supernatant fraction, this soluble fraction was responsible for up to $30 \%$ of the seeding activity and was PK sensitive (Figs. 2, 3). Similarly, PK resistance was initially thought to be an important feature of infectious prions (McKinley et al., 1983), but more recent studies reveal that PK-sensitive PrP aggregates also are pathogenic, suggesting a range of infectious PrP species (Safar et al., 1998; Pastrana et al., 2006; Gambetti et al., 2008; Colby et al., 2010).

Small $\mathrm{A} \beta$ aggregates provide relatively more molecular interfaces for templated misfolding and efficient propagation compared to larger aggregates or fibrils. Thus, a higher fibrillogenic activity of small, soluble $A \beta$ species compared to larger, insoluble assemblies would be predicted (Lee et al., 2007; Shankar and Walsh, 2009; Keshet et al., 2010). This view is supported by the present finding that extended sonication of $A \beta$-containing brain extract, i.e., fragmentation of larger $\beta$-amyloid assemblies into numerous smaller seeds, increases the seeding activity of the extract, in line with in vitro studies of amyloidogenic proteins (Soto et al., 2002; Knowles et al., 2009; Xue et al., 2009). Similarly, for prions, nonfibrillar small particles were found to be the most infectious agent, and sonication has been reported to increase prion infectivity (Silveira et al., 2005).

In $\mathrm{AD}$ research, a variety of pathogenic $\mathrm{A} \beta$ species have been described, ranging from $A \beta$ dimers to larger oligomers, protofibrils, and fibrils (for review, see Haass and Selkoe, 2007; Glabe, 2008). In most studies of $A D$ postmortem brain samples, the soluble pools consisting of small $A \beta$ aggregates were found to correlate highly with $\mathrm{AD}$ severity and progression (Lue et al., 1999; McLean et al., 1999; Wang et al., 1999; Tomic et al., 2009; Mc Donald et al., 2010). In the present study, the morphological appearance of the induced $\beta$-amyloid deposits differed between the soluble and insoluble fractions. The $\beta$-amyloid deposits induced by the insoluble and PK-treated brain extracts were rather large and frequently congophilic aggregates that appeared to be nonuniformly distributed throughout the injected area. In contrast, the soluble $\mathrm{A} \beta$ species from brain extracts induced smaller, more often Congo red-negative patches of $A \beta$ aggregates with a more homogeneous distribution throughout the injected region. Similarly, fragmentation of seeds by extended sonication induced smaller and more punctate $\beta$-amyloid deposits compared to the original, briefly sonicated extract. While these findings imply that the size of the seeds influences the nature of the induced deposits, the distributional and morphological differences of the induced lesions may also represent a difference in diffusion/transport of the larger, bulkier, insoluble $\mathrm{A} \beta$ seeds versus the smaller soluble seeds. In all cases, and independent of the morphological appear- 
ance, the congophilic aggregates were similarly surrounded by activated microglia, hypertrophic astrocytes, and dystrophic neurites, as previously described (Meyer-Luehmann et al., 2006). The relatively delayed emergence of Congo red-positive plaques in mice receiving the soluble material suggests either a different time course of initiation following seeding, and/or that these lesions eventually develop from the diffuse plaques.

In summary, the $\beta$-amyloid-inducing activity of brain extracts containing aggregated $\mathrm{A} \beta$ can be attributed to multiple entities with varying degrees of $\mathrm{PK}$ resistance or sensitivity. While insoluble pools of $A \beta$ clearly are capable of seeding $\beta$-amyloidosis in vivo, brain extracts also contain soluble $\mathrm{A} \beta$ assemblies that we found to be super-proportionally active in inducing $\beta$-amyloidosis. The existence of soluble, bioactive $\mathrm{A} \beta$ seeds raises the possibility that these agents may mediate the spread of $\beta$-amyloidosis within the brain, and that they could serve as diagnostic biomarkers in biological fluids such as CSF or plasma. There is increasing evidence that $\mathrm{A} \beta$ deposition in the brain precedes the clinical symptoms of AD by many years (Holtzman et al., 2011). Sensitive and reliable identification of the earliest forms of pathogenic $A \beta$ assemblies has the potential to expand the window for preventive interventions, and to refine current therapeutic strategies specifically targeting the initial and most pathogenic $\mathrm{A} \beta$ seeds.

\section{References}

Aguzzi A, Rajendran L (2009) The transcellular spread of cytosolic amyloids, prions, and prionoids. Neuron 64:783-790.

Aguzzi A, Heikenwalder M, Polymenidou M (2007) Insights into prion strains and neurotoxicity. Nat Rev Mol Cell Biol 8:552-561.

Bondolfi L, Calhoun M, Ermini F, Kuhn HG, Wiederhold KH, Walker L, Staufenbiel M, Jucker M (2002) Amyloid-associated neuron loss and gliogenesis in the neocortex of amyloid precursor protein transgenic mice. J Neurosci 22:515-522.

Calhoun ME, Burgermeister P, Phinney AL, Stalder M, Tolnay M, Wiederhold KH, Abramowski D, Sturchler-Pierrat C, Sommer B, Staufenbiel M, Jucker M (1999) Neuronal overexpression of mutant amyloid precursor protein results in prominent deposition of cerebrovascular amyloid. Proc Natl Acad Sci U S A 96:14088-14093.

Colby DW, Prusiner SB (2011) Prions. Cold Spring Harb Perspect Biol 3:a006833.

Colby DW, Wain R, Baskakov IV, Legname G, Palmer CG, Nguyen HO, Lemus A, Cohen FE, DeArmond SJ, Prusiner SB (2010) Proteasesensitive synthetic prions. PLoS Pathog 6:e1000736.

Collinge J, Clarke AR (2007) A general model of prion strains and their pathogenicity. Science 318:930-936.

Du D, Murray AN, Cohen E, Kim HE, Simkovsky R, Dillin A, Kelly JW (2011) A kinetic aggregation assay allowing selective and sensitive amyloid-beta quantification in cells and tissues. Biochemistry 50:16071617.

Duyckaerts C, Delatour B, Potier MC (2009) Classification and basic pathology of Alzheimer disease. Acta Neuropathol 118:5-36.

Eisele YS, Bolmont T, Heikenwalder M, Langer F, Jacobson LH, Yan ZX, Roth K, Aguzzi A, Staufenbiel M, Walker LC, Jucker M (2009) Induction of cerebral beta-amyloidosis: intracerebral versus systemic Abeta inoculation. Proc Natl Acad Sci U S A 106:12926-12931.

Eisele YS, Obermüller U, Heilbronner G, Baumann F, Kaeser SA, Wolburg H, Walker LC, Staufenbiel M, Heikenwalder M, Jucker M (2010) Peripherally applied Abeta-containing inoculates induce cerebral beta-amyloidosis. Science 330:980-982.

Gambetti P, Dong Z, Yuan J, Xiao X, Zheng M, Alshekhlee A, Castellani R, Cohen M, Barria MA, Gonzalez-Romero D, Belay ED, Schonberger LB, Marder K, Harris C, Burke JR, Montine T, Wisniewski T, Dickson DW, Soto C, Hulette CM, et al. (2008) A novel human disease with abnormal prion protein sensitive to protease. Ann Neurol 63:697-708.

Glabe CG (2008) Structural classification of toxic amyloid oligomers. J Biol Chem 283:29639-29643.

Haass C, Selkoe DJ (2007) Soluble protein oligomers in neurodegeneration: lessons from the Alzheimer's amyloid beta-peptide. Nat Rev Mol Cell Biol 8:101-112.

Hardy J, Selkoe DJ (2002) The amyloid hypothesis of Alzheimer's disease: progress and problems on the road to therapeutics. Science 297:353-356.

Harper JD, Lansbury PT Jr (1997) Models of amyloid seeding in Alzheimer's disease and scrapie: mechanistic truths and physiological consequences of the time-dependent solubility of amyloid proteins. Annu Rev Biochem 66:385-407.

Holtzman DM, Morris JC, Goate AM (2011) Alzheimer's disease: the challenge of the second century. Sci Transl Med 3:77sr1.

Jucker M, Walker LC (2011) Pathogenic protein seeding in Alzheimer's disease and other neurodegenerative disorders. Ann Neurol. Advance online publication. doi:10.1002/ana.22615.

Kane MD, Lipinski WJ, Callahan MJ, Bian F, Durham RA, Schwarz RD, Roher AE, Walker LC (2000) Evidence for seeding of $\beta$-amyloid by intracerebral infusion of Alzheimer brain extracts in beta-amyloid precursor protein-transgenic mice. J Neurosci 20:3606-3611.

Keshet B, Yang IH, Good TA (2010) Can size alone explain some of the differences in toxicity between beta-amyloid oligomers and fibrils? Biotechnol Bioeng 106:333-337.

Knowles TP, Waudby CA, Devlin GL, Cohen SI, Aguzzi A, Vendruscolo M, Terentjev EM, Welland ME, Dobson CM (2009) An analytical solution to the kinetics of breakable filament assembly. Science 326:1533-1537.

Lansbury PT Jr (1997) Structural neurology: are seeds at the root of neuronal degeneration? Neuron 19:1151-1154.

Lee S, Fernandez EJ, Good TA (2007) Role of aggregation conditions in structure, stability, and toxicity of intermediates in the Abeta fibril formation pathway. Protein Sci 16:723-732.

Lue LF, Kuo YM, Roher AE, Brachova L, Shen Y, Sue L, Beach T, Kurth JH, Rydel RE, Rogers J (1999) Soluble amyloid beta peptide concentration as a predictor of synaptic change in Alzheimer's disease. Am J Pathol 155:853-862.

Mc Donald JM, Savva GM, Brayne C, Welzel AT, Forster G, Shankar GM, Selkoe DJ, Ince PG, Walsh DM (2010) The presence of sodium dodecyl sulphate-stable Abeta dimers is strongly associated with Alzheimer-type dementia. Brain 133:1328-1341.

McKinley MP, Bolton DC, Prusiner SB (1983) A protease-resistant protein is a structural component of the scrapie prion. Cell 35:57-62.

McLean CA, Cherny RA, Fraser FW, Fuller SJ, Smith MJ, Beyreuther K, Bush AI, Masters CL (1999) Soluble pool of Abeta amyloid as a determinant of severity of neurodegeneration in Alzheimer's disease. Ann Neurol 46:860-866.

Meyer-Luehmann M, Coomaraswamy J, Bolmont T, Kaeser S, Schaefer C, Kilger E, Neuenschwander A, Abramowski D, Frey P, Jaton AL, Vigouret JM, Paganetti P, Walsh DM, Mathews PM, Ghiso J, Staufenbiel M, Walker LC, Jucker M (2006) Exogenous induction of cerebral beta-amyloidogenesis is governed by agent and host. Science 313:1781-1784.

Nesterenko MV, Tilley M, Upton SJ (1994) A simple modification of Blum's silver stain method allows for 30 minute detection of proteins in polyacrylamide gels. J Biochem Biophys Methods 28:239-242.

Nordstedt C, Näslund J, Tjernberg LO, Karlström AR, Thyberg J, Terenius L (1994) The Alzheimer A beta peptide develops protease resistance in association with its polymerization into fibrils. J Biol Chem 269:3077330776.

Paravastu AK, Qahwash I, Leapman RD, Meredith SC, Tycko R (2009) Seeded growth of beta-amyloid fibrils from Alzheimer's brain-derived fibrils produces a distinct fibril structure. Proc Natl Acad Sci U S A 106:7443-7448

Pastrana MA, Sajnani G, Onisko B, Castilla J, Morales R, Soto C, Requena JR (2006) Isolation and characterization of a proteinase K-sensitive PrPSc fraction. Biochemistry 45:15710-15717.

Powers ET, Morimoto RI, Dillin A, Kelly JW, Balch WE (2009) Biological and chemical approaches to diseases of proteostasis deficiency. Annu Rev Biochem 78:959-991.

Roychaudhuri R, Yang M, Hoshi MM, Teplow DB (2009) Amyloid betaprotein assembly and Alzheimer disease. J Biol Chem 284:4749-4753.

Safar J, Wille H, Itri V, Groth D, Serban H, Torchia M, Cohen FE, Prusiner SB (1998) Eight prion strains have $\operatorname{PrP}(\mathrm{Sc})$ molecules with different conformations. Nat Med 4:1157-1165.

Shankar GM, Walsh DM (2009) Alzheimer's disease: synaptic dysfunction and Abeta. Mol Neurodegener 4:48.

Silveira JR, Raymond GJ, Hughson AG, Race RE, Sim VL, Hayes SF, Caughey 
B (2005) The most infectious prion protein particles. Nature 437:257261.

Söderberg L, Dahlqvist C, Kakuyama H, Thyberg J, Ito A, Winblad B, Näslund J, Tjernberg LO (2005) Collagenous Alzheimer amyloid plaque component assembles amyloid fibrils into protease resistant aggregates. FEBS J 272:2231-2236

Soto C, Saborio GP, Anderes L (2002) Cyclic amplification of protein misfolding: application to prion-related disorders and beyond. Trends Neurosci 25:390-394.

Stalder AK, Ermini F, Bondolfi L, Krenger W, Burbach GJ, Deller T, Coomaraswamy J, Staufenbiel M, Landmann R, Jucker M (2005) Invasion of hematopoietic cells into the brain of amyloid precursor protein transgenic mice. J Neurosci 25:11125-11132.

Sturchler-Pierrat C, Abramowski D, Duke M, Wiederhold KH, Mistl C, Rothacher S, Ledermann B, Bürki K, Frey P, Paganetti PA, Waridel C, Calhoun ME, Jucker M, Probst A, Staufenbiel M, Sommer B (1997) Two amyloid precursor protein transgenic mouse models with Alzheimer disease-like pathology. Proc Natl Acad Sci U S A 94:13287-13292.

Tennent GA, Lovat LB, Pepys MB (1995) Serum amyloid P component pre- vents proteolysis of the amyloid fibrils of Alzheimer disease and systemic amyloidosis. Proc Natl Acad Sci U S A 92:4299-4303.

Tomic JL, Pensalfini A, Head E, Glabe CG (2009) Soluble fibrillar oligomer levels are elevated in Alzheimer's disease brain and correlate with cognitive dysfunction. Neurobiol Dis 35:352-358.

Wadsworth JD, Asante EA, Collinge J (2010) Review: contribution of transgenic models to understanding human prion disease. Neuropathol Appl Neurobiol 36:576-597.

Walker LC, Levine H 3rd, Mattson MP, Jucker M (2006) Inducible proteopathies. Trends Neurosci 29:438-443.

Wang J, Dickson DW, Trojanowski JQ, Lee VM (1999) The levels of soluble versus insoluble brain Abeta distinguish Alzheimer's disease from normal and pathologic aging. Exp Neurol 158:328-337.

Watts JC, Giles K, Grillo SK, Lemus A, DeArmond SJ, Prusiner SB (2011) Bioluminescence imaging of Abeta deposition in bigenic mouse models of Alzheimer's disease. Proc Natl Acad Sci U S A 108:2528-2533.

Xue WF, Hellewell AL, Gosal WS, Homans SW, Hewitt EW, Radford SE (2009) Fibril fragmentation enhances amyloid cytotoxicity. J Biol Chem 284:34272-34282. 